Revista Brasileira de Farmacognosia Brazilian Journal of Pharmacognosy 21(6): 986-990, Nov./Dec. 2011

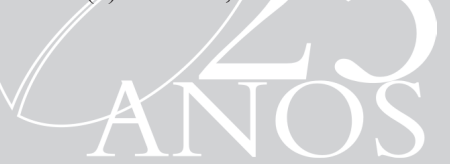

Article

Received 3 Aug 2010

Accepted 30 Dec 2010

Available online 22 Aug 2011

Keywords:

Artemisia scoparia

Artemisia spicigera

Asteraceae

DPPH

antimalaria

insecticide

ISSN 0102-695X

http://dx.doi.org/10.1590/S0102-

$695 \times 2011005000144$

\section{Evaluation of antimalarial, free-radical- scavenging and insecticidal activities of Artemisia scoparia and A. spicigera, Asteraceae}

\author{
Fariba H. Afshar, ${ }^{1,2}$ Abbas Delazar, ${ }^{1,2}$ Omar Janneh, ${ }^{3}$ Hossein \\ Nazemiyeh, ${ }^{4}$ Ardalan Pasdaran, ${ }^{4}$ Lutfun Nahar, ${ }^{5}$ Satyajit D. \\ Sarker,6
}

\begin{abstract}
${ }^{I}$ Drug Applied Research Center, Tabriz University of Medical Sciences, Tabriz, Iran, ${ }^{2}$ Biotechnology Research Center, Tabriz University of Medical Sciences, Tabriz, Iran, ${ }^{3}$ Department of Biomolecular and Sport Science, Coventry University, England, UK, ${ }^{4}$ School of Pharmacy, Tabriz University of Medical Sciences, Tabriz, Iran,

${ }^{5}$ Drug Discovery and Design Research Division, Department of Pharmacy, School of Applied Sciences, University of Wolverhampton, West Midland, UK,

${ }^{6}$ Department of Pharmacy, School of Applied Sciences, University of Wolverhampton, West Midland, UK.
\end{abstract}

\begin{abstract}
Artemisia species (Asteraceae), widespread throughout the world, are a group of important medicinal plants. The extracts of two medicinal plants of this genus, Artemisia scoparia Waldst. \& Kit. and A. spicigera C. Koch, were evaluated for potential antimalarial, free-radical-scavenging and insecticidal properties, using the heme biocrystallisation and inhibition assay, the DPPH assay and the contact toxicity bioassay using the pest Tribolium castaneum, respectively. The methanol extracts of both species showed strong free-radical-scavenging activity and the RC50 values were 0.0317 and $0.0458 \mathrm{mg} / \mathrm{mL}$, respectively, for A. scoparia and A. spicigera. The dichloromethane extracts of both species displayed a moderate level of potential antimalarial activity providing IC50 at 0.778 and $0.999 \mathrm{mg} / \mathrm{mL}$ for A. scoparia and A. spicigera, respectively. Both species of Artemisia showed insecticidal properties. However, A. spicigera was more effective than A. scoparia.
\end{abstract}

\section{Introduction}

The genus Artemisia L., one of the largest and most widely distributed genera of the family Asteraceae, comprises about 200-400 species of herbs and shrubs, the most notable being $A$. апnиa for producing the antimalarial drug artemisinin (Lee et al., 2000; Kim et al., 2002; GRIN Database, 2010). Artemisia species are distributed in the northern hemisphere, especially, along the Mediterranean coast of Europe, Southwest of Asia and Africa (Trease \& Evans, 2002; Salido et al., 2004; Ferchichi et al., 2006). This genus, with its common Persian name "Dermane" and the common English name "Wormwood", includes approximately 34 species that are found wild all over Iran (Mozaffarian, 1996; Ghasemi et al., 2007). Several coumarins, flavonoids, phenylpropanoids, sterols and terpenoids (specially sesquiterpenes and monoterpenes), and their glycosides were isolated from this genus, and shown to have antimalarial, antiviral, antitumor, antipyretic, antihaemorrhagic, anticoagulant, antiinflammatory, antioxidant, antihepatitis, antiulcerogenic, antispasmodic and anticomplementary activities (Kim et al., 2002; Lee et al., 2003).

Artemisia scoparia Waldst. \& Kit. (common name: "Redstem wormwood") and A. spicigera C. Koch (common name: "Sluggish wormwood") are two Iranian species, the former being a faintly scented slender branched biennial herb, and the latter an odorous plant (Mozaffarian, 1996). While A. scoparia possesses anticholesterolemic, antipyretic, antiseptic, antibacterial, cholagogue, diuretic, purgative and vasodilator properties (Safaei-Ghomi et al., 2005; Mirjalili et al., 2007; Singh et al., 2009), A. spicigera has antiseptic and stomachic properties (Guvenalp et al., 1998). The essential oils of $A$. scoparia show strong insecticidal activity against stored-product insects (Negahban et al., 2006), and that of $A$. spicigera has significant antioxidant property (CanBaser \& Buchbauer, 2009). As part of our on-going phytochemical and bioactivity studies on medicinal plants from Iran (Razvi et al., 2008; Modaressi et 
al., 2009; Nazemiyeh et al., 2009; Asnaashari et al., 2010; Delazar et al., 2006, 2007, 2010a-c), we now report on the antimalarial, free-radical-scavenging and insecticidal activities of different extracts of $A$. scoparia and $A$. spicigera.

\section{Material and Methods}

\section{Plant material}

The aerial parts of Artemisia scoparia Waldst. \& Kit. and A. spicigera C. Koch, Asteraceae, were collected from a place near the Aras river and Jolfa at E: $45^{\circ} 17^{\prime}$, $\mathrm{N}$ : $38^{\circ} 39^{\prime}$ (altitude of 700-750) in Eastern Azerbaijan province (Iran) during November 2009. The identity of the plants was confirmed by anatomical examination in comparison with the herbarium specimens (voucher nos. TUM-ADE 702 and TUM-ADE 705, respectively) retained in the School of Pharmacy, Tabriz University of Medical Science, Iran.

\section{Extraction}

Air-dried and ground aerial parts of $A$. scoparia and $A$. spicigera (120 g each) were individually Soxhletextracted successively, with n-hexane, dichloromethane (DCM) and methanol (MeOH) (1.1 L each). All these extracts were separately concentrated using a rotary evaporator at a maximum temperature of $45^{\circ} \mathrm{C}$.

Heme biocrystallisation and inhibition assay for potential antimalarial activity

The potential antimalarial activity of plant extracts was evaluated by the method described by Fitch et al. (1999) with some modifications (Tripathi et al., 2004). Briefly, varying concentrations $(0-2 \mathrm{mg} / \mathrm{mL}$ in $10 \%$ DMSO) of the extracts were incubated with $300 \mu \mathrm{M}$ of hematin (freshly dissolved in $0.1 \mathrm{M} \mathrm{NaOH}$ ), $10 \mathrm{mM}$ oleic acid and $10 \mu \mathrm{M} \mathrm{HCl}$. The reaction volume was adjusted to $1000 \mu \mathrm{L}$ using $500 \mathrm{mM}$ sodium acetate buffer, $\mathrm{pH}$ 5. Chloroquine diphosphate was used as a positive control. The samples were incubated overnight at $37{ }^{\circ} \mathrm{C}$ with regular shaking. After incubation, samples were centrifuged (14,000 x g, 10 min, at $21^{\circ} \mathrm{C}$ ) and the hemozoin pellet repeatedly washed with sonication $\left(30 \mathrm{~min}\right.$, at $21{ }^{\circ} \mathrm{C}$; FS100 bath sonicator; Decon Ultrasonics Ltd.) in $2.5 \%$ (w/v) SDS in phosphate buffered saline followed by a final wash in $0.1 \mathrm{M}$ sodium bicarbonate, $\mathrm{pH}$ 9.0, until the supernatant was clear (usually 3-5 washes). After the final wash, the supernatant was removed and the pellets were re-suspended in $1 \mathrm{~mL}$ of $0.1 \mathrm{M} \mathrm{NaOH}$ before determining the hemozoin content by measuring the absorbance at $400 \mathrm{~nm}$ (Beckmann DU640 spectrophotometer) using a $1 \mathrm{~cm}$ quartz cuvette. The results were recorded as \% inhibition (I\%) of heme polymerization/crystallization compared to positive control (chloroquine) using the following formula: $\mathrm{I} \%=$ $[(\mathrm{AB}-\mathrm{AA}) / \mathrm{AB}] \times 100$, where $\mathrm{AB}$ : absorbance of blank; AA: absorbance of test samples.

\section{Free-radical-scavenging activity}

The hydrogen atoms or electrons donation ability of the extracts was determined spectrophotometrically by the bleaching of purple coloured methanolic solution of DPPH (2,2-diphenyl-1-picrylhydrazyl) as a reagent (Takao et al., 1994). 2,2-Diphenyl-1-picrylhydrazyl, molecular formula $\mathrm{C}_{18} \mathrm{H}_{12} \mathrm{~N}_{5} \mathrm{O}_{6}$, was obtained from Sigma-Aldrich (Germany). DPPH (4 mg) was dissolved in $\mathrm{MeOH}(50 \mathrm{~mL})$ to obtain a concentration of $80 \mu \mathrm{g} / \mathrm{mL}$. The $\mathrm{MeOH}$ extracts of plants were dissolved in $\mathrm{MeOH}$ and the n-hexane and DCM extracts were in chloroform to obtain a concentration of $1 \mathrm{mg} / \mathrm{mL}$. Dilutions were made to obtain concentrations of $0.25,0.125,0.0625,0.03125,0.015625,0.0078125$, $0.00390625,0.001953125,0.000976563,0.000488281$ $\mathrm{mg} / \mathrm{mL}$. Diluted solutions were mixed with DPPH $(1 \mathrm{~mL})$ and allowed to stand for 30 min for any reaction to occur. The UV absorbance of samples and blank (without sample) was recorded at $517 \mathrm{~nm}$. The experiment was performed in duplicate and the average absorption was noted for each concentration. The same procedure was followed for the positive control, quercetin. Percent inhibition of the free radical DPPH (I \%) was calculated in the following way: $\mathrm{I} \%=[(\mathrm{AB}-\mathrm{AA}) / \mathrm{AB}] \times 100$, where $\mathrm{AB}$ : absorbance of blank; AA: absorbance of test samples. Concentration providing 50\% inhibition ( $\mathrm{RC} 50$ ) was calculated from the graph plotting inhibition percentage against test sample concentrations (Takao et al., 1994; Delazar et al., 2006; Kumarasamy et al., 2007).

\section{Insecticidal activity assay}

\section{Insects}

Adults of Tribolium castaneum (red flour beetle) were supplied from a laboratory culture, which were reared on a mixture of whole wheat flour and maize flour at the ratio of $1: 1$ in glass containers containing $0.5 \mathrm{~kg}$ of the mixture. All species were reared at $27 \pm 2{ }^{\circ} \mathrm{C}, 12 \%$ moisture content in continuous darkness for about three weeks without exposing to insecticides. Adults used in the experiments were 1-3 weeks old and of mixed sex.

\section{Insecticidal activity}

The insecticidal activity of the $n$-hexane, DCM and $\mathrm{MeOH}$ extracts of $A$. scoparia and $A$. spicigera was evaluated by the method described previously (Loschiavo et al., 1963) with minor modification (Freedman et al., 1982). The extracts were prepared at concentrations of 
20, 40 and $80 \mathrm{mg} / \mathrm{mL}$ in respective extraction solvents. The filter paper $(9 \mathrm{~cm}$ of diameter) received $1 \mathrm{~mL}$ of these extracts, and was placed on a Petri dish ( $9 \mathrm{~cm}$ of diameter). The control was treated with pure solvents. Solvent was allowed to evaporate. Ten non-sexed adults of Tribolium castaneum (Tenebrionidae) were placed in each Petri dish, maintained under $27 \pm 0.5^{\circ} \mathrm{C}, 12 \%$ moisture content and 12 $\mathrm{h}$ photo phase. The experimental design was completely randomized, with three replicates. Insect mortality was evaluated after $4,8,24,48 \mathrm{~h}$ of exposure to impregnated filter paper. Beetle responses to treated discs versus control discs were converted to "percentage of mortality".

\section{Statistical analysis}

Data was analyzed by one way ANOVA using SPSS-12 for Windows. Differences in means were estimated by means of repetitive measures followed by Bonferroni and Dunnet's post hoc test and expressed as statistical mean \pm standard deviation. Differences between means were regarded significant at $p<0.05$.

\section{Results and Discussion}

Malaria-infected erythrocytes are characterized by a high rate of production of ferriprotoporphyrin IX (heme) as a result of the ingestion and digestion of host cell haemoglobin (Famin et al., 1999). The parasite utilizes hemoglobin as its primary food source during intraerythrocytic development and proliferation (Francis et al., 1997). Heme is released as a toxic material of this process (Tripathi et al., 2001). It affects cellular metabolism by inhibiting enzymes, peroxidizing membranes and producing oxidative free radicals (Rathore et al., 2006). An important mechanism for the detoxification of heme is the formation of dark micro crystals of hemozoin in the food vacuoles of malaria parasites, and commonly referred to as malaria pigment (Kalkanidis et al., 2002; Egan \& Ncokazi, 2005; Rathore et al., 2006). Earlier this process used to be known as "heme polymerization" (Tripathi et al., 2001). It has been revealed that the structure of hemozoin (and its synthetic equivalent, $\beta$-hematin) is a cyclic dimer of ferriprotoporphyrin IX (heme). Several studies have shown that chloroquine and most of other antimalarial compounds inhibit $\beta$-hematin formation under different conditions (Egan \& Ncokazi, 2005). The heme biocrystallization and inhibition assay is based on the above facts (Fitch et al., 1999; Tripathi et al., 2004).

In this study the extracts of $A$. scoparia and $A$. spicigera were assessed for potential antimalarial activity using the heme biocrystallization and inhibition assay. The $n$-hexane and the $\mathrm{MeOH}$ extracts of both plants did not show any significant inhibition of heme biocrystallization properties. Unexpectedly, the extracts promoted heme bioscyrstallization, suggesting the lipid-like properties of this extract. However, the DCM extracts of $A$. scoparia and $A$. spicigera, in comparison with the blank, showed significant potential antimalarial effects (Figure 1). At lower concentrations $(0.1-0.4 \mathrm{mg} / \mathrm{mL})$, the observed absorbances of the DCM extracts were higher than the blank which might be a consequence of other fatty acids present in extracts causing synergistic effect with oleic acid in the test. At higher concentrations $(>0.4 \mathrm{mg} / \mathrm{mL})$, the DCM extracts inhibited heme biocrystallization. At higher concentrations $(>0.4 \mathrm{mg} / \mathrm{mL})$, the DCM extracts illustrated potent antimalarial effects. The IC50 values of the DCM extracts were 0.778 (A. scoparia) and 0.999 (A. spicigera) $\mathrm{mg} / \mathrm{mL}$ and that of the positive control chloroquine was $0.043 \mathrm{mg} / \mathrm{mL}$.

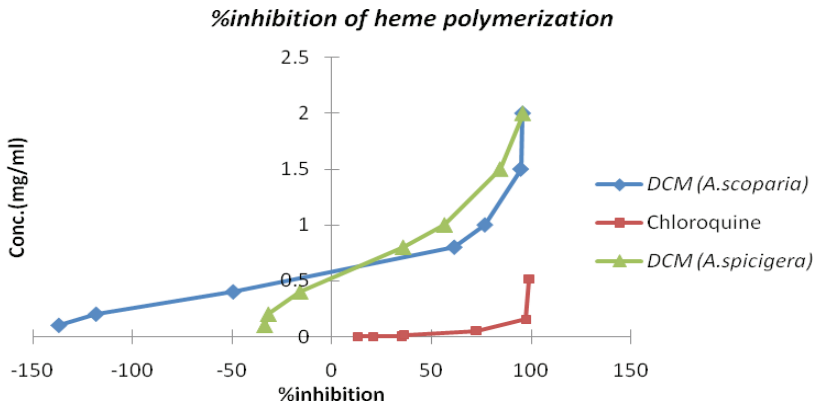

Figure 1. Comparison of $\%$ inhibition of heme polymerization between dichloromethane extracts of $A$. scoparia and $A$. spicigera, and chloroquine solution.

The free-radical-scavenging activity of the extracts of the aerial parts of A. scoparia and A. spicigera were evaluated in vitro by the DPPH assay. In this assay, the extracts were able to reduce the stable radical $\mathrm{DPPH} \cdot$ to the yellow colored diphenylpicrylhydrazine. The method is based on the reduction of methanolic DPPH solution in the presence of a hydrogen-donating scavenger through the formation of the non-radical form DPPD-H (Kumarasamy et al., 2007). All test extracts were capable of scavenging DPPH free radicals and exhibited a concentration-dependent activity pattern. The order free-radical-scavenging potency of the extracts were $\mathrm{MeOH}>\mathrm{DCM}>n$-hexane (Table 1 ). The extracts of A. scoparia were more potent than those of A. spicigera. Quercetin, a known natural free-radical scavenger, was used as a positive control. The DPPH radical-scavenging activities of the $\mathrm{MeOH}$ extracts were quite remarkable and comparable to that of quercetin [RC50 values $0.0317 \pm 0.5$ $\mathrm{mg} / \mathrm{mL}$ (A. scoparia), $0.0458 \pm 0.5 \mathrm{mg} / \mathrm{mL}$ (A. spicigera) and $0.0039 \pm 0.5 \mathrm{mg} / \mathrm{mL}$ (quercetin). Polar extracts $(\mathrm{MeOH})$ exhibited stronger activity than non-polar extracts. The $\mathrm{MeOH}$ extracts might contain phenolics compounds, e.g. flavonoids, coumarins or phenylpropanoids, which might have contributed toward the significant free-radicalscavenging activity of these extracts. 
Table 1. Free-radical-scavenging activity of the extracts of A. scoparia and A. spicigera determined by the DPPH assay.

\begin{tabular}{llc}
\hline Test samples & & RC50 values in $\mathrm{mg} / \mathrm{mL}$ \\
\hline A. scoparia & $n$-Hexane & 0.4128 \\
& DCM & 0.1210 \\
& MeOH & 0.0317 \\
A. spicigera & $n$-Hexane & 1.5616 \\
& DCM & 1.1336 \\
& $\mathrm{MeOH}$ & 0.0458 \\
Quercetin & & 0.0039 \\
\hline
\end{tabular}

Both Artemisia species showed insecticidal effects (Table 2). However, effect of $A$. spicigera was greater than that of $A$. scoparia. Among the extracts of A. spicigera, the DCM extract displayed the most potent activity. Previous studies reported the insecticidal effect of terpenoids and phenylpropanoids present in different species of Artemisia (Abdelgaleil et al., 2008; Liu et al., 2010). The possible presence of such compounds in the DCM extract of $A$. spicigera might be responsible for the insecticidal activity, as these compounds are better extracted by DCM.

Table 2. Percent mortality of Tribolium castaneum exposed to $1 \mathrm{~mL}$ of extracts of $A$. scoparia and A. spicigera at concentrations of 20,40 and $80 \mathrm{mg} / \mathrm{mL}$ after $4,8,24$ and 48 hours.

\begin{tabular}{|c|c|c|c|c|c|c|c|c|c|c|c|c|}
\hline \multirow{3}{*}{ Hours } & \multicolumn{6}{|c|}{ A. scoparia } & \multicolumn{6}{|c|}{ A. spicigera } \\
\hline & \multicolumn{2}{|c|}{$n$-Hexane } & \multicolumn{2}{|c|}{ DCM } & \multicolumn{2}{|c|}{$\mathrm{MeOH}$} & \multicolumn{2}{|c|}{$n$-Hexane } & \multicolumn{2}{|c|}{ DCM } & \multicolumn{2}{|c|}{$\mathrm{MeOH}$} \\
\hline & $\mathrm{mg} / \mathrm{mL}$ & $\%$ Mortality & $\mathrm{mg} / \mathrm{mL}$ & $\%$ Mortality & $\mathrm{mg} / \mathrm{mL}$ & $\%$ Mortality & $\mathrm{mg} / \mathrm{mL}$ & $\%$ Mortality & $\mathrm{mg} / \mathrm{mL}$ & $\%$ Mortality & $\mathrm{mg} / \mathrm{mL}$ & $\%$ Mortality \\
\hline \multirow[t]{3}{*}{4} & 20 & 0 & 20 & 0 & 20 & 0 & 20 & 3.3 & 20 & 20 & 20 & 0 \\
\hline & 40 & 3.3 & 40 & 0 & 40 & 0 & 40 & 0 & 40 & 13.3 & 40 & 0 \\
\hline & 80 & 0 & 80 & 0 & 80 & 0 & 80 & 0 & 80 & 3.3 & 80 & 0 \\
\hline \multirow[t]{3}{*}{8} & 20 & 3.3 & 20 & 3.3 & 20 & 0 & 20 & 10 & 20 & 23.3 & 20 & 0 \\
\hline & 40 & 3.3 & 40 & 0 & 40 & 3.3 & 40 & 6.6 & 40 & 20 & 40 & 0 \\
\hline & 80 & 0 & 80 & 0 & 80 & 3.3 & 80 & 0 & 80 & 13.3 & 80 & 0 \\
\hline \multirow[t]{3}{*}{24} & 20 & 3.3 & 20 & 6.6 & 20 & 0 & 20 & 10 & 20 & 23.3 & 20 & 0 \\
\hline & 40 & 3.3 & 40 & 0 & 40 & 3.3 & 40 & 10 & 40 & 23.3 & 40 & 3.3 \\
\hline & 80 & 0 & 80 & 0 & 80 & 3.3 & 80 & 3.3 & 80 & 13.3 & 80 & 0 \\
\hline \multirow[t]{3}{*}{48} & 20 & 3.3 & 20 & 6.6 & 20 & 0 & 20 & 10 & 20 & 33.3 & 20 & 0 \\
\hline & 40 & 3.3 & 40 & 3.3 & 40 & 3.3 & 40 & 13.3 & 40 & 30 & 40 & 6.6 \\
\hline & 80 & 0 & 80 & 0 & 80 & 3.3 & 80 & 3.3 & 80 & 13.3 & 80 & 0 \\
\hline
\end{tabular}

\section{References}

Abdelgaleil SAM, Abbassy MA, Belal ASH, Abdel Rasoul MAA 2008. Bioactivity of two major constituents isolated from the essential oil of Artemisia judaica $\mathrm{L}$. Bioresource Technol 99: 5947-5950.

Asnaashari S, Delazar A, Alipour SS, Nahar L, Williams AS, Pasdaran A, Mojarab M, Fatih-Azad F, Sarker SD 2010. Chemical composition, free-radical-scavenging and insecticidal activities of the aerial parts of Stachys byzantine. Arch Biol Sci 62: 653-662.

Can Baser KH, Buchbauer G 2009. Hand book of essential oils. Science, Technology and Applications, CRC press (Taylor and Francis group), pp. 261.

Delazar A, Biglari F, Nazemiyeh H, Talebpour A, Imani Y, Nahar, L, Sarker SD 2006. GC-MS analysis of the essential oils, and the isolation of phenylpropanoid derivatives from the aerial parts of Pimpinella aurea. Phytochemistry 67: 2176-2181.

Delazar A, Naseri M, Nazemiyeh H, Talebpour A-H, Imani Y, Nahar L, Sarker SD 2007. Flavonol 3-methyl ether glycosides and a tryptophylglycine dipeptide from Artemisia fragrans (Asteraceae), Biochem Syst Ecol 35: 52-56.
Delazar A, Khodaie L, Afsar J, Nahar L, Sarker SD 2010a. Isolation and free-radical-scavenging properties of cyanidin 3-O-glycosides from the fruits of Ribes biebersteinii Berl. Acta Pharmaceut 60: 1-11.

Delazar A, Nazifi E, Movafeghi A, Nazemiyeh H, Hemmati S, Nahar L, Sarker SD 2010b. Analyses of phytosterols and free radical scavengers from the bulbs of Ornithogalum cuspidatum Bertol. BLACPMA 9: 87-92.

Delazar A, Lasheni S, Fathi-Azad F, Nahar L, Rahman MM, Asnaashari S, Mojarab M, Sarker SD 2010c. Free radical scavenging flavonol 3-O-glycosides from the leaves of Ribes biebersteinii Berl. Rec Nat Prod 4: 96-100.

Egan TJ, Ncokazi KK 2005. Quinoline antimalarials decrease the rate of $\beta$-hematin formation. J Inorg Biochem 99: 1532-1539.

Famin O, Krugliak M, Ginsburg H 1999. Kinetics of inhibition of glutathione-mediated degradation of ferriprotoporphyrin IX by anti-malarial drugs. Biochem Pharmacol 58: 59-68.

Ferchichi L, Merza J, Landreau A, Le Ray AM, Legseir B, Seraphin D, Richomme P 2006. Occurrence of isocoumarinic and phenolic derivatives in Artemisia campestris L. subsp. campestris. Biochem Syst Ecol 34: 829-832. 
Fitch CD, Cai GZ, Chen YF, Shoemaker JD 1999. Involvement of lipids in ferriprotoporphyrin IX polymerization in malaria. Biochim Biophys Acta 1454: 31-37.

Francis SE, Sullivan DJ, Goldberg DE 1997. Hemoglobin metabolism in the malaria parasite Plasmodium falciparum. Annu Rev Microbiol 51: 97-123.

Freedman B, Mikolajczak KL, Smith Jr. CR, Kwolek WF, Burkholder WE 1982. Olfactory and aggregation responses of Oryzaephilus surinamensi (L.) to extracts from oats. J Stored Prod Res 18: 75-82.

Ghasemi E, Yamini Y, Bahramifar N, Sefidkon F 2007. Comparative analysis of the oil and supercritical $\mathrm{Co}_{2}$ extract of Artemisia sieberi. J Food Eng 79: 306-311.

GRIN Taxonomy Databases 2010. USDA, ARS, National Genetic Resources Program. Germplasm Resources Information Network - (GRIN), National Germplasm Resources Laboratory, Beltsville, Maryland. Available on-line at: http://www.ars-grin.gov/cgi-bin/npgs/ html/splist.pl?997

Guvenalp Z, Cakir A, Harmandar M, Gleispach H 1998. The essential oil of Artemisia austriaca Jacq. and Artemisia spicigera C. Koch. from Turkey. Flavour Fragr J 13: 26-28.

Kalkanidis M, Klonis N, Tilley L, Deady LW 2002. Novel phenothiazine anti-malarials: synthesis, anti-malarial activity and inhibition of the formation of $\beta$-hematin, Biochem Pharmacol 63: 833-842.

Kim JH, Kim HK, Jeon SB, Son KH, Kim EH, Kang SK, Sung ND, Kwon BM 2002). New sesquiterpenemonoterpene lactone, artemisolide, isolated from Artemisia argyi. Tetrahedron Lett 43: 6205-6208.

Kumarasamy Y, Byres M, Cox PJ, Jaspars M, Nahar L, Sarker SD 2007. Screening seeds of some Scottish plants for free-radical scavenging activity, Phytotherapy Res 21: 615-621.

Lee SH, Kang HM, Song HC, Lee H, Lee UC, Son KH, Kim SH, Kwon BM 2000. Sesquiterpene lactones, inhibitors of faransyl protein transferase, isolated from the flower of Artemisia sylvatica. Tetrahedron 56: 4711-4715.

Lee SH, Lee MY, Kang HM, Han DC, Son KH, Yang DC, Sung ND, Lee CW, Kim HM, Kwon BM 2003; Antitumor activity of the faransyl-protein transferase inhibitors, arteminolides, isolated from Artemisia. Bioorgan Med Chem 11: 4545-4549.

Liu ZL, Chu SS, Liu QR 2010. Chemical composition and insecticidal activity against Sitophilus zeamais of the essential oils of Artemisia capillaries and Artemisia mongolica. Molecules 15: 2600-2608.

Loschiavo SR, Beck SD, Norris DM 1963. Behavioral responses of the smaller European elm bark beetle, Scalytus multistriatus (Coleoptera: Scolytidae) to extracts of elm bark. Ann Entomol Soc Am 56: 764-8.

Mirjalili MH, Tabatabaei SMF, Hadian J, Nejad-Ebrahimi S, Sonboli A 2007. Phenological variation of the essential oil of Artemisia scoparia Waldst. et Kit. from Iran, $J$ Essent Oil Res 19: 326-329.

Modaressi M, Delazar A, Nazemiyeh H, Fathi-Azad E, Smith E, Rahman MM, Gibbons S, Nahar L, Sarker SD 2009. Antibacterial iridoid glucosides from Eremostachys laciniata. Phytotherapy Res 23: 99-103.

Mozaffarian V 1996. A Dictionary of Iranian Plant Names. Farhange Moaser.Tehran, Iran, pp. 56-58.

Nazemiyeh H, Delazar A, Movahedin N, Jodari M, Imani Y, Ghahramani M-A, Nahar L, Sarker SD 2009. Free radical scavengers from the aerial parts of Grammosciadium platycarpum and GC-MS analysis of the essential oils from its fruits. Rev Bras Farmacogn 19: 914-918.

Negahban M, Moharramipour S, Sefidkon F 2006. Chemical composition and insecticidal activity of Artemisia scoparia essential oil against three Coleopteran stored-product insects. J Asia-Pacific Entomol 9: 381-388.

Rathore D, Jani D, Nagrakatti R, Kumar S 2006. Heme detoxification and anti-malarial drugs - known mechanisms and future prospects. Drug Discov Today Ther Strateg 3: 153-158.

Razvi SM, Nazemiyeh H, Hajiboland R, Kumarasamy Y, Delazar A, Nahar L, Sarker SD 2008. Coumarins from the aerial parts of Prangos uloptera (Apiaceae). Rev Bras Farmacogn 18: 1-5.

Safaei-Ghomi J, Bamoniri A, Sarafraz MB, Batooli H 2005. Volatile components from Artemisia scoparia Waldst et Kit growing in central Iran. Flavour Frag J 20: 650-652.

Salido S, Valenzuela LR, Altarejos J. Nogueras M, Sanchez A, Cano E 2004. Composition and infraspecific variability of Artemisia herba-alba from southern Spain. Biochem Syst Ecol 32: 265-277.

Singh HP, Mittal S, Kaur S, Batish DR, Kohli RK 2009. Chemical composition and antioxidant activity of essential oil from residues of Artemisia scoparia. Food Chem 114: 642-645.

Takao T, Watanabe N, Yagi I, Sakata K 1994. A simple screening method for antioxidants and isolation of several antioxidants produced marine bacteria from fish and shellfish. Biosci Biotech Bioch 58: 17801783.

Trease GE, Evans WC 2002. Trease \& Evans Pharmacognosy, $15^{\text {th }}$ edition, Baillieve Tindall, London, pp. 411-412.

Tripathi AK, Gupta A, Garg SK, Tekwani BL 2001. In vitro $\beta$-hematin formation assays with plasma of mice infected with Plasmodium yoelii and other parasite preparations comparative inhibition with quinoline and endoperoxide antimalarials. Life Sci 69: 2725-33.

Tripathi AK, Khan SI, Walker LA, Tekwani BL 2004. Spectrophotometric determination of the novo hemozoin/ $\beta$-hematin formation in an in vitro assay, Anal Biochem 325: 85-91.

\section{*Correspondence}

\section{Satyajit D. Sarker}

Department of Pharmacy, School of Applied Sciences, University of Wolverhampton

MM Building, Molineux Street, Wolverhampton WV1 1SB, West Midland, UK

s.sarker@wlv.ac.uk

Tel. +44 (0) 1902322578 